\title{
O feminismo no Brasil: suas múltiplas faces
}

\author{
Uma história do feminismo no \\ Brasil.
}

PINTO, Céli Regina Jardim.

São Paulo: Fundação Perseu Abramo, 2003. 119 p. (Coleção História do Povo Brasileiro).

Céli Regina Jardim Pinto tem formação em história e é doutora em ciência política pela Universidade de Essex, na Inglaterra. É professora na Universidade Federal do Rio Grande do Sul, onde desenvolve suas atividades de docência e pesquisa, tendo sido coordenadora do Programa de Pós-Graduação em Ciência Política. Atualmente, orienta dissertações e teses e coordena projetos de pesquisa sobre as relações entre as organizações não-governamentais (ONGs), principalmente as ONGs feministas, a sociedade civil e o Estado. Publicou livros e artigos no Brasil e no exterior sobre os espaços públicos e a participação política da mulher no Brasil, além de trabalhos e livros de análise do discurso político brasileiro.

No livro Uma história do feminismo no Brasil, organizado em quatro capítulos e baseado em informações das escritoras do feminismo Albertina Costa, Anette Goldberg, Mary Castro, Moema Toscano, Mirian Goldberg, Mirian Grossi, Miriam Moreira Leite, Schuma Shumaher, Sonia Álvares e Vera Soares, Céli Pinto sinaliza que são múltiplos os objetivos, as manifestações e as pretensões do feminismo brasileiro. Em decorrência de ser um movimento difuso, nessa obra, destaca as principais tendências, situando-as em dois momentos: o primeiro, do final do século XIX até 1932, é o período tratado no primeiro capítulo; o segundo, do feminismo pós-1968, abordado nos outros três capítulos.

No primeiro capítulo, "Em busca da cidadania", Céli Pinto discorre sobre o conjunto diverso de manifestações do movimento feminista, identificando duas tendências, que tiveram início no final do século XIX e se estenderam pelas três primeiras décadas do século XX. A primeira tendência teve como foco o movimento sufragista liderado por Bertha Lutz. Chama essa tendência de feminismo "bem comportado" para sinalizar o 
caráter conservador desse movimento, o qual não questionava a opressão da mulher. Nesse sentido, a luta para a inclusão das mulheres à cidadania não se caracterizava pelo desejo de alteração das relações de gênero, mas como um complemento para o bom andamento da sociedade.

Céli Pinto chama a segunda tendência de feminismo "malcomportado", vertente que reúne uma gama heterogênea de mulheres (intelectuais, anarquistas, líderes operárias) que, além do político, defendem o direito à educação e falam em dominação masculina, abordam temas que para a época eram delicados, como, por exemplo, a sexualidade e o divórcio. Há uma terceira vertente que a autora chama de "o menos comportado dos feminismos", que se manifesta especificamente no movimento anarquista e no Partido Comunista, tendo como expoente Maria Lacerda de Moura. Ademais, a fundação do Partido Republicano Feminino, em 1910, a fundação da Federação Brasileira para o Progresso Feminino (FBPF), em 1918, o jornalismo feminista e o feminismo anarquista são tópicos tratados nesse capítulo.

Com o golpe de 1937 ocorre um longo período de refluxo do movimento feminista que se estende até as primeiras manifestações nos anos 1970. No entanto, isso não significa que durante esse longo período as mulheres não tiveram nenhum papel no mundo público; muito pelo contrário, houve momentos importantes de participação da mulher, como o movimento no início da década de 1950 contra a alta do custo de vida, por exemplo. Céli Pinto, ao longo dos capítulos aborda esses grupos de mulheres de forma circunstancial em decorrência de seu objetivo principal que, segundo ela, é o de destacar os grupos feministas, isto é, os que problematizaram e lutaram pela transformação da condição de dominação à qual as mulheres estavam submetidas.

No segundo capítulo, "O novo feminismo nasce da ditadura", a autora centra-se na década de 1970. A emergência do feminismo em pleno governo Médici determinou que ele surgisse dentro e fora do país e em boa parte no exílio. Na Europa e nos Estados Unidos havia cenários de grande efervescência política, de revolução dos costumes, de radical renovação cultural, enquanto no Brasil o clima era de ditadura militar, repressão e morte. As características que o movimento feminista teve nos dois hemisférios estão intimamente ligadas a esses cenários, sendo que os primeiros grupos feministas em 1972, em São Paulo e no Rio de
Janeiro, foram inspirados no feminismo do Hemisfério Norte.

Em 1972 ocorrem eventos que apontam para a história e as contradições do feminismo no Brasil: o congresso promovido pelo Conselho Nacional da Mulher, liderado pela advogada Romy Medeiros, e as primeiras reuniões de grupos de mulheres em São Paulo e no Rio de Janeiro, de caráter quase privado, o que seria uma marca do novo feminismo no Brasil.

A presença de Romy Medeiros indica uma espécie de transição entre o velho e o novo feminismo, entre o que já se chamava de feminismo "bem-comportado", à moda Bertha Lutz, e um novo feminismo "malcomportado" que começou a enfrentar questões consideradas tabus. Entre os eventos que marcaram a entrada definitiva das mulheres e das questões por elas levantadas, na esfera pública, destaca-se ainda - Ano Internacional da Mulher, em 1975, decretado pela Organização das Nações Unidas (ONU). O feminismo no Brasil se fortalece com o evento organizado para comemorar o Ano Internacional, realizado no Rio de Janeiro sob o título "O papel e o comportamento da mulher na realidade brasileira", e com a criação do Centro de Desenvolvimento da Mulher Brasileira.

Esse evento foi organizado com base em dois grupos informais e isso é particularmente importante, pois, além de informais, esses grupos tinham caráter privado, quase de um encontro de amigas. Foram esses grupos que se reuniram, buscaram o patrocínio da ONU e montaram o citado evento que se tornou um marco na história do feminismo no país. Esse evento suscitou resistências por parte dos poderes constituídos conforme $o$ atesta 0 depoimento de uma das organizadoras: "inventamos o nome pomposo de 'Pesquisas sobre o papel e o comportamento da mulher brasileira' para não usar o termo 'feminista', que assustava as pessoas" (p. 57). $O$ ano de 1975 foi também o da organização do Movimento Feminino pela Anistia, fundado por Terezinha Zerbini. As mulheres exiladas nos Estados Unidos e na Europa voltavam para o Brasil trazendo uma nova forma de pensar sua condição de mulher, em que somente os papéis de mãe, companheira e esposa (submissa e dócil) não mais serviam.

No terceiro capítulo, "O feminismo na redemocratização", Céli Pinto centra-se na década de 1980 e demonstra de que forma o feminismo enfrentou a redemocratização. Diz que duas questões tiveram de ser enfrentadas: a unidade do movimento ameaçada pela reforma partidária de 1979, que dividiu as oposições, e a 
relação do movimento feminista com os governos democráticos que viriam a se estabelecer, principalmente quando o Partido do Movimento Democrático Brasileiro (PMDB) começou a ganhar as eleições estaduais.

Surgiram grupos feministas temáticos, como também houve espaço para o surgimento e o desenvolvimento do que se poderia chamar de feminismo acadêmico, ancorado no Departamento de Pesquisa da Fundação Carlos Chagas, em São Paulo, e em pesquisas de ciências humanas e educação realizadas nas grandes universidades do país, em algumas das quais surgiram Núcleos de Pesquisa em Estudos da Mulher.

A partir de 1985, foram criadas as delegacias especializadas. O feminismo, as feministas e as delegacias da mulher não resolveram a questão da violência, mas a criação das delegacias foi um avanço na medida em que a mulher passou a ser reconhecida como vítima de violência. O segundo tema que se tornou central no movimento feminista a partir da década de 1980 foi a implantação do Programa de Atenção Integral à Saúde da Mulher (PAISM), pelo Ministério da Saúde, que envolvia três temas: planejamento familiar, sexualidade e aborto.

No quarto e último capítulo, "A virada do milênio", Céli Pinto aborda o movimento feminista a partir da década de 1990, salientando, porém, que não pretende abarcar todas as manifestações do feminismo na contemporaneidade. Sinaliza dois cenários importantes para a identificação das novas formas que o pensamento e o movimento feminista tomaram: o primeiro refere-se à dissociação entre o pensamento feminista e o movimento; o segundo, à profissionalização do movimento por meio do aparecimento de um grande número de ONGs, a mais pública expressão do feminismo na virada do século. Cita, como exemplos da atuação das ONGs, algumas organizações: o Centro Feminista de Estudos e Assessoria (CCFMEA), criado em 1989, com sede em Brasília (www.cfemea.org.br); as ações em Gênero, Cidadania e Desenvolvimento (AGENDE), igualmente com sede em Brasília. Tanto o CCFMEA e a AGENDE atuam na esfera da alta política. Já a Articulação da Mulher Brasileira (AMB), criada para preparar a ida das mulheres brasileiras à Conferência Mundial de Pequim em 1995, atua como contraponto, assessorando e organizando os movimentos de base. Outra ONG, formada em 1991, foi a Rede Nacional Feminista de Saúde e Direitos Reprodutivos conhecida como Rede Saúde, que congrega 110 filiadas em 20 estados.
Cita ainda a Cidadania, Estudo, Pesquisa, Informação e Ação (CEPIA), a Assessoria Jurídica (THEMIS) e o Comitê Latino-Americano e do Caribe para a Defesa dos Direitos da Mulher (CLADEM). Menciona, como significativa, a página eletrônica do Governo Federal na Internet, uma seção com informações sobre projetos em debate no Congresso Nacional, sobre programas em ministérios e informações em geral relativas aos direitos das mulheres (www.redegoverno.gov.br/ mulhergoverno).

Céli Pinto ressalta um tipo de organização que atua no campo da política e não se relaciona diretamente com o Estado, mas principalmente com as mulheres das camadas populares, organizando-as e buscando aumentar o seu poder para agirem na esfera pública. A GELEDÉS, por exemplo, tem uma forte atuação contra o racismo envolvendo homens e mulheres, e entre os seus programas encontram-se as oficinas de sexualidade e saúde, o Projeto Rapper e o SOS Corpo, de Recife. Igualmente, cita que, entre as ONGs ligadas à Associação Brasileira de ONGs (ABONG), é possível verificar uma multiplicidade de manifestações de mulheres em movimentos populares, em sindicatos e em partidos políticos, que trazem para a discussão as questões dos direitos das mulheres.

Embora saliente a importância das ONGs como uma nova forma de arena política, Céli Pinto aponta os limites dessas organizações, como, por exemplo, a necessidade de se guiarem pela agenda das fundações internacionais em função dos critérios para o recebimento de fundos e a institucionalização. Faz um alerta ao dizer que a tendência para a profissionalização por meio de ONGs pode estar indicando a volta de um "feminismo bem-educado".

Finalizando, pode-se inferir que, ao evidenciar a existência de múltiplas identidades e de um feminismo difuso na sociedade, Céli Pinto vislumbra que o sujeito na história não é mais o de uma figura universal, tendo o homem como o protagonista. A presente obra está inserida no contexto da História Social, uma vez que a abordagem está voltada para a história das mulheres. De uma forma didática, a autora elabora uma síntese sobre os marcos dos grupos institucionalizados. Embora a expansão e os limites desses movimentos organizados não sigam uma operação direta ou linear, a narrativa de Céli Pinto segue uma forma linear ao tecer considerações sobre a existência desses grupos, apresentando uma visão geral das várias tendências do feminismo no Brasil. Os leitores e as leitoras, porém, têm a tarefa de nuançar os pensamentos, a forma 
historiográfica em cada uma dessas tendências.

É necessário pensar tais tendências como um estudo dinâmico na política de produção do conhecimento. A obra de Joan Scott e Judith Butler, Feminists Theorize the Political, por exemplo, é composta de artigos nos quais se demonstra o modo de como abordar o feminismo do ponto de vista da política e da teoria ao mesmo tempo. Há que se ressaltar, na abordagem da autora, a renovação teórica na ampliação dos horizontes acerca das múltiplas faces do feminismo no Brasil, assim como a criação e a historicização das subjetividades, o modo como as relações entre os sexos foram construídas em determinado tempo histórico e contexto político.

Enfim, Céli Pinto preocupa-se com a vertente dos movimentos organizados com vistas à conquista da cidadania - os movimentos feministas. A abordagem diz respeito às mulheres notáveis, as que se destacaram no campo da política. Entrementes, existe a vertente das abordagens posteriores à irrupção da história social, como, por exemplo, o enfoque ao cotidiano, ao trabalho, entre outros. Nessa linha estão os trabalhos de Natalie Z. Davis, Michelle Perrot, Maria Odila da Silva Dias, autoras que buscam desmistificar concepções vinculadas à submissão e à docilidade, apontando para as táticas de resistência e de sobrevivência encetadas pelas mulheres.

Embora esse trabalho esteja inserido nas discussões contemporâneas acerca da história do feminismo no Brasil, as múltiplas faces desse movimento requerem um relato mais complexo. As discussões atuais em torno das contribuições recíprocas entre a história das mulheres e a do movimento feminista e também das construções sociais acerca do gênero apontam para uma maior complexidade.

Claricia Otto Universidade Federal de Santa Catarina 